\title{
Sustainable practices in urban freight distribution in Bilbao
}

\author{
Esther Álvarez, Alberto de la Calle \\ Faculty of Engineering, University of Deusto, Bilbao (SPAIN) \\ esther.alvarez@deusto.es; acalle@deusto.es
}

Received June 2010

Accepted September 2011

\section{Abstract:}

Purpose: The objective of the present study is to select some feasible and sustainable logistic practices in order to improve the urban freight distribution in Bilbao city.

Design/methodology/approach: After a thorough literature review and a benchmarking, Analytic Hierarchy Process (AHP) techniques were used in order to support the decision making processes in order to select the most interesting practices. The criteria used for this selection were based on four factors: (1) improvement of the city freight distribution, (2) implementation possibility, (3) short and medium term applicability and (4) impact on the citizens of Bilbao.

Findings: The paper identifies some specific problems that must be faced during the last stage of the logistics chain, where products are usually delivered to final customers in the urban environment.

Research limitations/implications: Not all good urban freight distribution practices can be applied universally to all types of towns. Therefore, it is necessary to design some practices specifically to each particular city according to the physical characteristics of the city, the companies' motivation and the citizens' habits.

Practical implications: All the agents involved in the city freight distribution should be aware of the benefits and problems that their actions cause. 
Originality/value: This study was carried out from a wide perspective that included researchers, logistics operators and local authorities.

Keywords: AHP, urban freight distribution, last-mile logistics, city

\section{Introduction}

Urban freight distribution is characterized by being a totally differentiated type of road transport. In this type of transport concepts like environmental sustainability and good service becomes more important than transit times or vehicle capacity optimization.

From the perspective of the types of vehicles used in last-mile logistics, they are generally smaller than those used for long distance road transport. But sometimes it could be interesting to utilize bigger vehicles inside cities, in order to optimize distribution costs and occupation of public roads. This practice is usually avoided due to the strict transport-policies developed by the regional and local governments regarding the circulation of big vehicles in the city centers.

Urban freight distribution is also a complex problem if it is analyzed from an integral perspective. Town councils, citizens, dealers, carriers, suppliers are involved in this issue. Each one tries to defend its own interests but these interests are often in conflict.

Considering the aforementioned facts, a characterization of urban freight distribution can be made, based on the following features:

- Agents involved: The concentration of a high number of interests involved in this concept makes urban logistics a multi-faceted problem. Although cooperation is one of the most commonly observed behavior it is usually studied between channel members and not with other agents (citizens, town-councils). Few studies and projects face this issue from a wide perspective.

- Relatively short routes: this type of transport usually requires relatively short routes and low speed driving, due both to the areas covered and the kind of goods being distributed. 
- Short time of effective driving: the working time of a driver is divided into: (a) the time when he/she drives the vehicle, which is much shorter than in road transport, and (b) the time when the driver makes freight delivery. This portion of time can by far surpass the driving time and usually represents a very significant part of the distribution costs. Therefore, a great part of the operations are made while the vehicle is stopped.

- Long vehicle downtime: It is typical that the driver parks the vehicle and makes a good part of the deliveries on foot. Although the worker is not driving, this needs to be considered as working time and thus should be regarded as a cost of urban goods distribution. This is the same focus that is applied by the so called Rules on Driving and Rest Times applicable to drivers.

- Labor intensive: Human resources represent one of the main vectors in the cost of urban freight distribution above fuel, maintenance and depreciation of vehicles, as well as other related expenses.

- Space restrictions: In city centers, the logistic configuration of space is of vital importance due to hard spatial limitations. The freight vehicle of two or three rigid axes is not usually allowed in these areas. Often, the delivery service in the area center can only be performed using reduced delivery vans size not exceeding 3.5 tons. This type of vehicle has a limited carrying capacity, leading to an overload of the road network and the impossibility of using it with certain distribution actors. Due to these limitations, in these areas it is not possible to park heavy goods vehicles over a long period of time.

- Traffic infrastructure: The high demand for transport in the city center (both freight and transportation of passengers) is opposed to the very limited supply of infrastructure of the metropolitan central areas. This is the cause of traffic jams, which in turn, delay the transport process. Developing new infrastructure is virtually impossible because of the high costs.

- Environmental aspects: In the city centers, transport should be carried out as respectfully of the environment as possible, due to the high density of population in these areas. So it is necessary to control pollutant emissions, in addition to create barriers against noise pollutions and control land use. 
Taking these features into account, it can easily be understood that in order to improve last-mile logistics, it will be necessary to design practices which adapt to each particular city, in this case, to Bilbao. This paper tries to describe some cityfreight-practices that are currently being applied in this town, and to specify the complexity of the decision process in which the most convenient practices have been determined.

The paper is organized as follows. Section 2 briefly reviews relevant literature about last-mile distribution, especially about initiatives in other European cities. Section 3 focuses on the selected practices. Finally, Section 4 gathers the conclusions.

\section{Previous studies}

In this section, previous national and international studies are presented. The first subsection exposes the available literature review. After this, the second subsection about the state of the art in this area of improving the supply chain through the last-mile distribution.

\subsection{Literature review}

There is not much theoretical content in the field of urban freight distribution if the problem is analyzed from a wide perspective (enterprise, carriers, dealers, citizens). In addition, the theoretical contents are scarce, possibly because the tests conducted at each location are difficult to extrapolate to other areas with different characteristics. However, there are some interesting references for improving freight distribution in Bilbao city.

The European Directorate-General for Energy and Transport published in 2007 a Green paper on urban mobility (European Commission, 2007). The European Commission wishes to open a debate with citizens and all relevant stakeholders at the local, regional, national and European levels on this topic due to the similar problems suffered by European cities: congestion, road safety, security, pollution, climate change, etc. Furthermore, the European Commission co-finance several initiatives with the aim of generating a decisive breakthrough by supporting and evaluating the implementation of ambitious integrated sustainable urban transport strategies that should make a real difference for the welfare of the European citizen. CIVITAS is one of them, that has been implemented in three phases: CIVITAS I (2002), CIVITAS II (2005) and CIVITAS PLUS (2008) (www.civitasinitiative.net). Short Term Actions to Reorganize Transport of goods (START) was a 
European project funded by the European Commission (http://www.startproject.org). This project approach is based on close collaboration between the city government, transport companies and local businesses formalized in local freight networks. The networks will have periodic meetings where the activities and the progress of the project are discussed.

Regarding the academic perspective there are several investigations which are focused on urban freight distribution at the European level. Ambrosini and Routhier (2004) showed a comparative study of nine countries, contrasting the objectives, methodologies and results obtained in each of them. This non-extensive review shows that in spite of different framework methods and models, similar trends emerge at the economic and environmental levels.

Some other studies examine urban logistics centers, which try to identify the potential for the development of urban consolidation centers (UCCS) that have as their principal objective the alleviation of local environmental and traffic concerns in urban areas (Browne, Sweet, Woodburn \& Allen, 2005). These more specific studies have been of great help when planning to implement initiatives in Bilbao.

On the other hand, it is also necessary to analyze the possibility of creating partnerships between the private and public sector for urban freight distribution. Some authors (Browne, Nemoto, Visser \& Whiteing, 2004) review the increase in public-private partnerships (PPPs) in urban distribution in recent years. A discussion of various approaches to PPP is included in this research, together with the consideration of the forms that participation can take. This study considered the ways in which PPPs have been applied to urban distribution, with detailed examination of several strategies and policies. This analysis is also valid for the practices promoted in Bilbao. Other authors focused on the cooperation in channels of distribution (Gill \& Allerheiligen, 1996), highlighting the opportunities for increased channel profits due to cooperating in physical distribution. New governance structures that may enhance the efficiency and effectiveness of freight deliveries are needed (Holguín-Veras \& Paaswell, 2000). Their bases settle down on the magnitude of physical distribution costs.

Another aspect to consider, as already mentioned, is sustainability. In this sense, Lehmbrock, Spott and Beckmann (2007) believe that the contribution of urban transport planning to urban development and improving conditions in deprived urban neighborhoods is generally underestimated. Therefore, the study introduces concepts which illustrate how an integrated planning approach can improve mobility in urban neighborhoods without interfering with sustainable transport 
development in the city and the region as a whole. Moreover, the social, economic and environmental dimensions of sustainable transport development were given equal attention, as far as this was possible. The selection of good practice examples is limited to urban transport projects.

In a similar way, Dablanc (2008) also analyzes the way urban goods movements are included in transport policies aimed at improving air quality in large European cities, particularly in France. The main conclusion of this article is that this new type of environmental regulation targeted on lorries is the best way available for cities wishing to improve their environment and air quality. Considering the current structure of the freight industry, other policy instruments such as negotiated agreements with freight professionals cannot be very useful except in a limited number of cities.

Finally, it is important to note that all these considerations will have an effect on local trade, and that the evolution of commerce in Europe can contribute to the renaissance of European cities, as was discussed at The Second European Congress on Commerce and City (Balsas, 2001).

\subsection{Benchmarking}

In the absence of too many written references regarding the state of the art, a thorough benchmarking was undertaken. In this sense, we have conducted several studies that explore the successful initiative carried out in different European towns. One of the most well-known contributions is the Bestuf project (www.bestuf.net) that aims at creating an open European network to identify and disseminate best practices and success criteria with respect to urban freight transport. These initiatives have been studied because they are practices that involve a clear improvement in the urban freight distribution in those cities.

The study analyzed many practices developed all around Europe. From all of them, these are some key practices identified as feasible to be implemented in Bilbao city:

- Barcelona: Some interesting initiatives are temporal individual load spaces, silent night unload and an urban consolidation center. They have improved the supply chain by reducing time and cost, but also the coexistence of citizens and businesses has been improved.

- Málaga: Among other things, an urban consolidation center has been installed. In the opinion of those responsible for this distribution center, in 
the current situation and for maintaining the center with no losses there are two mandatory actions: (a) the local government must subsidize the parking rental fee, and (b) it should be compulsory for other players, such as beverage distributors, to carry out the distributions through the platform. But it is unclear whether these actions will be finally implemented. The main advantage of the system is the extension in time of the distribution schedules on a restricted area (old part of the city).

- La Rochelle: An Elcidis (Electric Vehicle City Distribution System) urban platform has been implemented. The activities in the Elcidis platform include:

o Transfer of goods from trailers or heavy vehicles to small vehicles better adapted to travel on the narrow streets of the old town.

o Functions of goods storage or warehousing. These functions are used with textile products and never with fresh or perishable products, because their facilities are not properly equipped to effectively maintain such goods.

o Home service distribution. It consists of transporting goods from the supermarkets and from the platform to the customer's home. The electric vans from ELCIDIS platform go directly to supermarkets where products are loaded and moved to their final destination.

\section{Practices for Bilbao}

Once the benchmarking was done, some meetings were conducted to select a total of nine practices that could be implemented in Bilbao city. The meetings were attended by dealers, carriers, wholesalers, supermarkets, local government, police and researchers from the University of Deusto. The result was the selection of nine practices identified as interesting for the city. The list of pre-selected practices is the following:

- Practice 1: Urban collection and delivery at night.

- Practice 2: Multi use lanes.

- Practice 3: Unification of regional city freight policies.

- Practice 4: Larger lorries. 
- Practice 5: Urban consolidation centers.

- Practice 6: Clean vehicles (eco-friendly vehicles).

- Practice 7: Temporal individual load and unload spaces.

- Practice 8: Underground service tunnel.

- Practice 9: Dynamic allocation of loading and unloading places.

The objective was to select the five most desirable practices to be developed taking into account the specific characteristics of Bilbao. The selection is mainly based on previous experiences in other cities, as well as on the estimation of benefits that will result in each of them. But usually each practice is not intended to satisfy all the agents involved in urban freight distribution. For example, the movement of loading and unloading operations to off-peak hours (Practice 1 ) is oriented to those agents which move an important number of pallets a day (supermarkets). On the other hand, Practice 7 means reserving a parking place for loading and unloading operations at individual businesses.

\begin{tabular}{|l|r|r|r|r|}
\hline Factors & $\begin{array}{l}\text { I mprovement } \\
\text { of the city } \\
\text { freight } \\
\text { distribution }\end{array}$ & $\begin{array}{l}\text { I mpact on } \\
\text { the citizens } \\
\text { of Bilbao }\end{array}$ & $\begin{array}{l}\text { I mplementation } \\
\text { possibility }\end{array}$ & $\begin{array}{l}\text { Short and } \\
\text { Medium } \\
\text { applicability }\end{array}$ \\
\hline $\begin{array}{l}\text { I mprovement } \\
\text { of the city } \\
\text { freight } \\
\text { distribution }\end{array}$ & 1.00 & 3.00 & 0.33 & 1.00 \\
\hline $\begin{array}{l}\text { I mpact on the } \\
\text { citizens of } \\
\text { Bilbao }\end{array}$ & 0.33 & 1.00 & 0.20 & 0.67 \\
\hline $\begin{array}{l}\text { I mplementatio } \\
\text { n possibility }\end{array}$ & 3.00 & 5.00 & 1.00 & 3.00 \\
\hline $\begin{array}{l}\text { Short and } \\
\text { Medium } \\
\text { applicability }\end{array}$ & 1.00 & 1.50 & 0.33 & 1.00 \\
\hline
\end{tabular}

Table 1. Peer comparison between the selected factors

Therefore, the AHP (Analytic Hierarchy Process) technique was used as a tool for supporting decision making processes. The AHP is a structured technique commonly used to deal with complex decisions. Rather than finding the right solution, it is based in obtaining decisions that meet the needs of those who have the problem. The AHP was carried out based on 4 factors: (1) improvement of the city freight distribution, (2) implementation possibility, (3) short and medium term applicability and (4) impact on the citizens of Bilbao. Based on these criteria and in order to prioritize them, peer comparison was made according to the relevance between them. This process was developed in accordance with the point of view of 
the agents involved in the project. Table 1 shows the relative importance of one factor over another, expressed following a scale from 1 to 9: 1-equal, 2-moderate, 5-strong, 7-strong, 9- extreme.

The first three factors are represented in the Figure 1 . The five most suitable practices regarding the factors analyzed are shown in this figure.

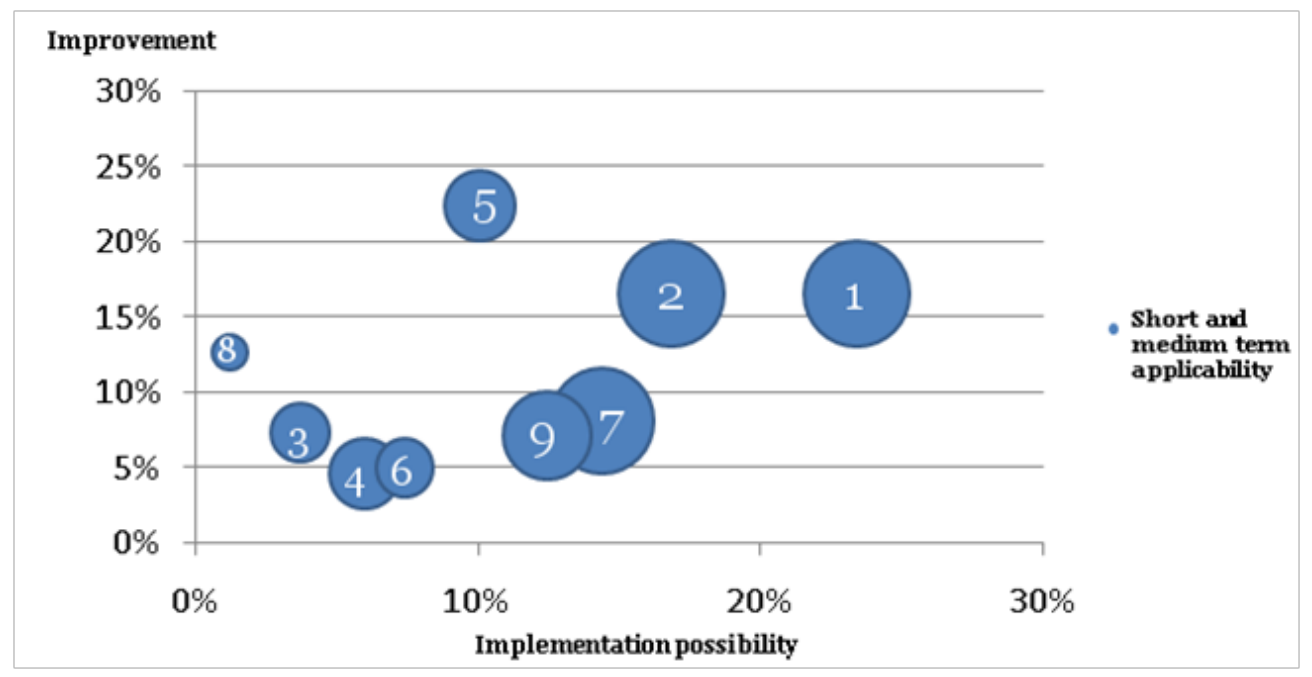

Figure 1. Results of the AHP technique

The five practices selected are the following:

- Practice 1: Urban collection and delivery at night.

- Practice 2: Multi-use lane.

- Practice 5: Urban consolidation centre.

- Practice 7: Temporal individual load spaces.

- Practice 9: Dynamic allocation of loading and unloading places.

After selecting the best five actions for Bilbao, a precise study of each one has been made, in order to ensure that they improve the supply chain, by benefiting all the agents in the system, including drivers, shops and people living around. Practices 1, 3 and 7 have already been studied and are now being applied in the city as pilot test. But Practices 5 and 9 are still being analyzed and feasibility plans are currently being developed. 


\subsection{Urban collection and delivery at night}

The aim of this initiative is to divert the delivery of certain goods that represent a high volume of vehicles to night-time, from $8 \mathrm{pm}$ to $8 \mathrm{am}$. The action will be supported with the use of larger trucks and cleaner vehicles. This action implies that the loading and unloading operations must be done in the street and that it will be necessary to develop a protocol so that the loading and unloading tasks are carried out properly. The protocol specifies the characteristics of the lorries (Euro 4 or Euro 5), the way in which the operations should be done, a number of good practices for drivers to avoid causing noise during the loading and unloading operations and so on.

This practice can also be supplemented with the use of adaptive limited speed and acceleration system. This system limits the ability to accelerate the vehicle, helping to limit excessive fuel consumption, a very common situation in urban transport in which about one third of fuel consumption occurs in starts and stops on vehicles. In addition, it can also be supplemented with the eco-driving system that helps drivers to behave more efficiently in terms of consumption. This action is presenting a very positive impact on the urban freight distribution and it has allowed the removal of a large number of vehicles and the improvement of the supply chain in terms of cost reduction and less environmental impact.

Although the initiative in Bilbao is now only a pilot test, it is expected, based on similar actions implemented in Barcelona and other European cities, that the fuel consumption reduction achieved will be about $15 \%$ or $20 \%$ of the actual consumptions. From five vehicles entering in Bilbao during the day, the objective is to do so with only 3 vehicles. This will have a positive effect on the distribution cost

It has been also estimated that the $\mathrm{CO}_{2}$ emissions will be reduced in around $20 \%$ of the actual emissions.

\subsection{Multi-use lane}

The aim of this initiative is to adapt the use of public roads to the different operational needs emerging during the day. The objective is that during the day there is a part of the street usable for freight loading and unloading, traffic and parking.

This initiative represents a relatively positive impact on urban freight distribution, since even though this practice does not involve the reduction of the number of freight vehicles during peak hours, it facilitates parking, loading and unloading 
activities. Therefore, traffic flow is improved and less time is spent by freight vehicles. It also has a high development possibility if local governments take part and responsibility on the action. This practice suits small deliveries, catering and supermarkets better than other types of freights. Through the establishment of a schedule for the multi-use lane it is possible to divert traffic from peak to off-peak hours, so that a smoother flow of heavy vehicle traffic is ensured. From this point of view, it is considered that it can produce a saving of approximately $10 \%$ of fuel consumption due to freight vehicles that are transferred to off-peak hours, and accelerations and stops reductions, and less time to find a parking place.

These data are based on estimated time savings that were measured in Barcelona, where this initiative was firstly implemented in Spain. Moreover, a reduction in $\mathrm{CO}_{2}$ emissions of $7 \%$ is estimated.

\subsection{Temporal individual load spaces}

The purpose of this practice is to reserve certain areas to specific distributors that can carry out loading and unloading activities. The parking place is exclusively reserved for specific time slots and limited to the expected arrival time of the vehicles. This will therefore be a practice oriented to lorries that come from their distribution centers but not to direct shop suppliers, who will have to use the conventional places of loading and unloading. This is an action that is presenting a very positive impact on urban freight distribution because it avoids illegal parking of trucks, and allows the use of such spaces for parking when unloading operations are not required.

It also has a high development potential because of the positive commitment of the distributors, but requires good surveillance by the authorities, at least in its initial development. It is a short term implementable practice since it does not require any special investment. Therefore, this initiative could be extended to new city areas in the near future.

Based on the experience in Barcelona, estimated savings in goods transport from the loading point to the unloading point vary widely. According to some samples taken, the time savings per unit of transported volume was $22 \%$, so in terms of fuel consumption it could be around $10 \%$ savings consumption and the consequent reduction of $\mathrm{CO}_{2}$ emissions. 


\subsection{Dynamic allocation of loading and unloading places}

In this case the objective is to reserve places for loading and unloading during the day in certain areas and time frames, so that certain dealers and distributors can ensure the vehicle a parking place to perform specific freight loading and unloading tasks. This action can present a positive impact on urban goods distribution since it will eliminate illegal parking on sidewalks or in double-parking. The process should be started by the carriers who via SMS or a telephone call can reserve a parking place in a specified street and time of arrival. The system will inform about the availability of that parking place on the requested time slot. This place is reserved for the carrier for 30 minutes. The problem of this action is the cost of the technology which should be used for ensuring the availability of the reserved parking space.

This practice has a high potential for development because it affects different supply chain agents, such as distributors, drivers, cafeterias or restaurants and so on. This action also makes a great progress on the supply chain distribution, because it ensures spaces to drivers and distributors so that they can make their loading and unloading activities without wasting time. So there is a reduction in costs and distribution time, and the supply chain is optimized from the costs point of view. The estimated savings would be similar to those obtained with temporal individual load spaces.

This initiative is still in a preliminary stage because of the high costs that involves and the complexity of the process.

\subsection{Urban consolidation center}

This practice entails the creation of a mini logistics center or store next to the most important commercial area of Bilbao. It will be operated mainly by private logistics operators. In the case of Bilbao this type of solution may be intended exclusively to the historic old city, because of supply difficulties in that area and the existence of small businesses requiring a high number of small-volume deliveries. Nowadays the time slot for making loading and unloading operations inside the old city of Bilbao is from $8 \mathrm{am}$ until $11 \mathrm{am}$, the rest of the day it is a pedestrian area. For shop managers, dealers, carriers and all the businesses involved in the movement of goods this schedule is considered to be too short. But if the local government decides to increase the time for these operations, it will mean a decrease in the life quality of shoppers, citizens, tourists and so on. Regarding the sectors benefited 
from this urban logistic center, they will be all with the exception of mass distribution. The reason is the huge volume of goods that they should move.

This action will be supported by the use of environmentally friendly, noiseless and small vehicles for the distribution from the urban logistic center to the different dealers. An extension of the supply time frame will complement this action, because these small vehicles are suitable for distributing at any time.

It is believed that this action will present a very positive impact on the urban goods distribution with the reduction of the concentration of vehicles in the old part of Bilbao, which in the end will benefit citizens and tourists. The initiative will succeed if all the agents involved use the distribution center to send and bring their goods.

The lack of facilities near the old part of Bilbao to host this urban consolidation center and the prize of the square meter are the main problems which should be faced.

From the supply chain point of view, this action is the most complex of the five presented in this paper. Some complexity comes from problems related to the responsibility of the deliveries, branding and costs. The urban consolidation center could be set up through different legal entity types: private, public or through a private-public agreement. In spite of the selected legal entity type, the urban consolidation center should be feasible from the economic, social and environmental perspectives. This involves the addition of a new agent in the supply chain, so in terms of costs they will increase. Despite this fact, benefits should be greater: the number of hours for loading and unloading operations will considerably increase, and the number of fines to the drivers will be reduced. Another option regarding cost problem could be adding new value to the operations of the urban consolidation center: using it not only as a cross-docking platform but as a storage-house for dealers or/and logistics operators that deliver parcels to people who live in the covered area.

Nevertheless, if potential users do not dispatch their goods through the urban consolidation center, the economic viability of the project will be seriously damaged. Branding and responsibility problems are linked. The small and environmental friendly vehicles will not share the brand of all the operators which could use them, so it will be necessary to reach some consensus between the different operators. If any problem happens during the transport process from the urban consolidation center to the goods destination, some questions arise: Who is 
responsible? Which brand is damaged? These problems should be answered before launching the urban consolidation center project.

\section{Conclusions}

As it has been noted, many people, pedestrians and drivers, organizations and local authorities are involved in one way or another on the city freight transportation. On the one hand, there are the citizens, who live the freight transportation as passive-actors. Although they are not directly involved in this activity, some of their actions can interfere with it, i.e. parking in areas reserved to loading and unloading operations. But sometimes freight companies also break the city rules: double-parking, use of pedestrian areas or zebra crossing to park the vehicle, use of the loading and unloading reserved areas longer than allowed, etc.

Five practices have been selected in order to be implemented in Bilbao as pilot cases. It should be highlighted that there is not a single solution that fits all the problems. From the literature review it is clear that what works in one city does not necessarily work in another. Even more, the solution provided by one practice does not suit all the agents involved in the city freight distribution. Some of them suit small deliveries better than other kind of deliveries, e.g. multi-use line, dynamic allocation of loading and unloading places and urban consolidation centers. On the other hand, the mass distribution could benefit from other initiatives like delivery at night and temporal individual load spaces. The number of agents involved, the physical characteristics of the city and the citizens' habits are the main variables in this complex problem.

The European Commission is also aware of this problem and since 2002 it has been developing different programs for financing research and projects in this topic. The green paper and other projects reports were included in the analysis of the state of the art together with other academic research papers. However, after analyzing different solutions adopted in other cities which could be similar to Bilbao characteristics, it was clear that a series of practices could be carried out to improve transport in the city.

Nine alternatives were proposed at first based on the typology of the city. Then a first study following the AHP technique was conducted in order to determine which ones would be the most appropriate for Bilbao, based on four factors. Besides, the five most suitable practices were selected. 
After that, some pilot tests were defined and an extensive study in each initiative was carried out in order to identify the agents involved, the end locations, the human and material necessary resources, and the advantages that could be gained. After this study, the next step will be to perform comprehensive testing. If the pilot tests give satisfactory results, it will be possible to implement these practices definitely, and even to apply the same actions in other areas of Bilbao. Having developed the necessary action protocols for each case, it will be easier to extend the initiatives to other areas of Bilbao and other companies that could be interested in the process.

\section{Acknowledgments}

The authors gratefully acknowledge the financial support of the Spanish Ministry of Public Works by means of grant 2008/247.

\section{References}

Ambrosini, C., \& Routhier, J.L. (2004). Objectives, Methods and Results of Surveys Carried out in the Field of Urban Freight Transport: An International Comparison. Transport Reviews: A Transnational Transdisciplinary J ournal, 24(1), 57-77.

Balsas, C. (2001). Commerce and the European City Center: Modernization, Regeneration and Management. European Planning Studies, 9(5), 677-682.

Browne, M., Nemoto, T., Visser, J., \& Whiteing, T. (2004). Urban freight movements and public-private partnerships. Paper presented at Third International Conference on City Logistics, Madeira.

Browne, M., Sweet, M., Woodburn, A., \& Allen, J. (2005). Urban Freight Consolidation Centres Final Report. University of Westminster.

Dablanc, L. (2008). Urban Goods Movement and Air Quality Policy and Regulation Issues in European Cities. Oxford Journal of Environmental Law, 20(2), 245-266. http://dx.doi.org/10.1093/jel/eqn005

European Commission. (2007). Green paper: Towards a new culture for urban mobility. http://www.ec.europa.eu/transport/urban/urban_mobility/urban_mobility_en.htm Accessed $11^{\text {th }}$ April 2011. 
Gill, L.E., \& Allerheiligen, R.P. (1996). Cooperation in channels of distribution: physical distribution leads the way. International Journal of Physical distribution \& Logistics, 26(5), 49-63.

Holguín-Veras, J., \& Paaswell, R.E. (2000). New York Regional Intermodal Freight Transportation Planning: Institutional Challenges. Transportation Law Journal, 27(3), 453-473.

Lehmbrock, M., Spott, M., \& Beckmann, K.J. (2007). Sustainable Urban Transport and deprived urban areas -Good Practice Examples in Europe. Berlin: German Institute of Urban Affairs.

Journal of Industrial Engineering and Management, 2011 (www.jiem.org)

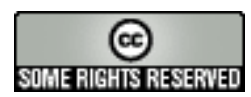

Article's contents are provided on a Attribution-Non Commercial 3.0 Creative commons license. Readers are allowed to copy, distribute and communicate article's contents, provided the author's and Journal of Industrial Engineering and Management's names are included. It must not be used for commercial purposes. To see the complete license contents, please visit http://creativecommons.org/licenses/by-nc/3.0/. 